\title{
Psychological distress and nutritional status in head and neck cancer patients: a pilot study
}

\author{
Maja Gosak ${ }^{1}$ Kaja Gradišar ${ }^{1}$ Nada Rotovnik Kozjek ${ }^{2}$ Primož Strojan ${ }^{1,3}$ (i)
}

Received: 7 September 2019 / Accepted: 18 January 2020 / Published online: 5 February 2020

(c) The Author(s) 2020

\begin{abstract}
Purpose To determine whether the psychological state of patients with head and neck cancer (HCN) is associated with their nutritional status.

Methods In 40 patients with locally advanced HNC treated with definitive or adjuvant (chemo)radiotherapy, psychological and nutritional status were assessed before treatment, at its completion and 3 months' post-therapy. Psychosocial distress was measured using the Hospital Anxiety and Depression Scale questionnaire (HADS-A, HADS-D), whereas the nutritional status was evaluated using standard methods (Nutritional Risk Screening Tool 2002, anthropometric data, dynamometry and laboratory tests) and with a bioelectrical impedance analysis parameter phase angle (PA).

Results Before treatment, more patients were screened positive for anxiety than at treatment completion $(p=0.037)$ or 3 months' post-therapy $(p=0.083)$. Depression prevalence was non-significantly higher at the end and after therapy. Compared to the baseline, more cachectic patients and a reduction of PA values were found at successive assessments. Anxiety was more often recorded among malnourished/cachectic patients (assessment $1, p=0.017$; assessment $2, p=0.020$ ) who were also found more frequently depressed (assessment $2, p=0.045$; assessment $3, p=0.023$ ). Significantly higher PA values were measured in patients without distress determined at 3 months' post-therapy by the HADS-A $(p=0.027)$.

Conclusion The association between the psychological and nutritional status found in this pilot study and the options for intervention warrants further clarification in a larger prospective trial.
\end{abstract}

Keywords Head and neck cancer $\cdot$ Radiotherapy $\cdot$ Chemotherapy $\cdot$ Nutrition $\cdot$ Psychological status

\section{Introduction}

Head and neck cancer (HNC) is the eighth most common cancer worldwide [1]. Despite the increasing etiological importance of human papillomavirus (HPV) infection observed in recent years, the long-lasting history of smoking and alcohol abuse is still the prevailing cause of this cancer, and reflects the lower socioeconomic status of the patients [2]. Consequently, the time from the symptoms' appearance and the first medical consultation is often delayed in

Primož Strojan

pstrojan@onko-i.si

1 Department of Radiation Oncology, Institute of Oncology, Zaloška 2, 1000 Ljubljana, Slovenia

2 Clinical Nutrition Unit, Institute of Oncology, Ljubljana, Slovenia

3 Faculty of Medicine, University of Ljubljana, Ljubljana, Slovenia these patients [3]. At presentation, two-thirds of them have a locally advanced disease with associated anatomical abnormalities and functional disorders in the affected area [2].

Facing the diagnosis of a malignant disease adversely influences the psychological profile of patients, which is further aggravated with troublesome symptoms of the disease and long-lasting and aggressive oncological treatment with associated toxic effects [4]. Thus, patients with HNC often face difficulties with social integration, which can lead to isolation and symptoms of depression and anxiety $[4,5]$. The risk of developing a mood disorder correlates with the patients' sex, age and size of tissue destruction, caused by either a tumor or treatment [5-7]. HNC patients were found to suffer from these symptoms more frequently than other cancer patients [8]. Moreover, at 1 year after treatment completion, studies showed the anxiety disorder still in every fifth patient (20\%) and the prevalence of depression of $17 \%$, whereas the suicide rate among these patients was more than 3 times higher than in the general population $[9,10]$. 
Nutritional disorders such as malnutrition, micronutrients deficiencies and cachexia are among the main consequences of inflammation and lower food intake that resulted from anatomic and functional changes in the upper aerodigestive tract caused by a tumor or treatment. HNC patients are at a high risk for malnutrition that affects about $50 \%$ of them at the time of disease presentation and closely correlates with the morbidity and mortality rates [11-13]. Also, malnutrition increases the risk of acute and late treatment-related complications which may adversely impact treatment efficacy and the chances of a cure $[11,14]$.

In the literature, there is only limited information on the relationship between the psychological and nutritional status of patients with HNC. Moreover, as pertinent studies were performed in different cultural and social environments, their practical value for other populations may be limited. When evaluating the results of these studies, it is essential to take into consideration the characteristics of the social and cultural environment from which the patients derive, and the associated system of values. Therefore, the aim of our pilot study was to determine whether the psychological state of Slovenian patients with $\mathrm{HCN}$ is associated with their nutritional status.

\section{Patients and methods}

\section{Patient eligibility}

Eligible patients were $\geq 18$-year-old men with histologically confirmed UICC TNM stage III-IVB (7th ed.) squamous cell carcinoma of the oral cavity, oropharynx, hypopharynx, or larynx, treated with definitive or postoperative (chemo) radiotherapy (RT) with a curative intent and $\geq 50$ Gy to the mucosa (inclusion of $\geq 75 \%$ of the oral and pharyngolaryngeal lining) and tissues of both sides of the neck. In patients treated with primary surgery, the surgical procedure comprised the resection of the primary tumor together with a surrounding margin of normal tissue and removal of the related regional lymph nodes on the neck. Patients with simultaneously diagnosed or previously treated malignancy (with the exception of a basal cell carcinoma of the skin), a pacemaker or defibrillator, severe chronic diseases (of the heart, lungs, liver, kidneys, gastrointestinal tract), active uncontrolled infection, neuromuscular disorders, hemiplegia and arthritis affecting the hands, were deemed ineligible due to the potential influence of these conditions to the results of the planned measurements and tests. Patients considered not being able to understand and complete the questionnaires were also excluded.

Linac-based intensity-modulated RT and concurrent weekly cisplatin $\left(40 \mathrm{mg} / \mathrm{m}^{2} \mathrm{IV}\right.$, in patients at high-risk for in-field recurrence) were employed as indicated by the
Multidisciplinary Head and Neck Tumor Board. Before treatment and weekly during the course of RT, a nutritional status was evaluated and undernourished patients were offered individual dietary counseling. Detailed information on the characteristics of patients (gender, age, co-morbidities), disease (site of the index cancer, histology, TNM stage), and treatment (definitive/postoperative, daily/total RT dose, chemotherapy) was prospectively collected.

\section{Study design and investigations}

The study protocol was approved by the Republic of Slovenia National Medical Ethics Committee (No. 46/02/15) and all patients signed a written informed consent after receiving detailed information about the study.

The study was designed as being prospective, with the planned inclusion of 40 patients who would complete all the planned investigations. In each patient, the psychological and nutritional status were assessed at three time points: 2-3 weeks before commencement of (chemo)RT, at the time of treatment completion, and 3 months' post-therapy.

The psychosocial distress was measured using the Hospital Anxiety and Depression Scale (HADS) questionnaire, which consists of two 7-item scales, HADS-A and HADS-D, asking patients about their immediate feelings. Each item was scored from 0 to 3 and subscale scores $>7$ are indicative of anxiety and depression [15]. The questionnaire was completed by the patients themselves, with two of the investigators $(\mathrm{MG}, \mathrm{KG})$ present to answer any queries.

The nutritional status was evaluated using standard methods (Nutritional Risk Screening Tool 2002 [NRS-2002], anthropometric data, dynamometry and laboratory tests) and with bioelectrical impedance analysis (BIA). Patients who collected $\geq 3$ points on the 7-point scale by the NRS2002 with an age-adjustment for patients aged $>70$ years were considered malnourished [16]. Cachectic patients were identified using the international consensus criteria, with a simple starvation excluded by the presence of three out of five criteria: decreased muscle strength, low fat-free mass index (FFMI, $<14.6 \mathrm{~kg} / \mathrm{m}^{2}$ ), anorexia, fatigue, and abnormal biochemistry indicating inflammation, anemia or hypoalbuminemia $[17,18]$. For this purpose, a body mass index (BMI) was calculated (weight $/ \mathrm{height}^{2}[\mathrm{~kg} /$ $\left.\mathrm{m}^{2}\right]$ ) and the hand-grip strength was measured with Jamar ${ }^{\circledR}$ Hand Dynamometer (Warrenville, IL, USA) as described elsewhere [19]. A fifth percentile normative grip strength values stratified by age and gender were used to determine decreased muscle strength [20]. Anemia, hypoalbuminemia or inflammation were diagnosed at concentrations of hemoglobin $<133 \mathrm{~g} / \mathrm{l}$, serum albumin $<35 \mathrm{~g} / \mathrm{l}$ and C-reactive protein $(\mathrm{CRP})>5 \mathrm{mg} / \mathrm{l}$. Based on the measurements and tests results, patients were categorized as well-nourished, malnourished or cachectic. 
The BIA was performed according to the standards of the National Health Institute using a Bodystat ${ }^{\circledR}$ Quadscan 4000 (Douglas, GB) as previously described, at an alternating electric current of $0.8 \mathrm{~mA}$ and four frequencies $(5,50$, 100 and $200 \mathrm{kHz}$ ) [19]. The phase angle (PA) and FFMI were calculated at $50 \mathrm{kHz}$ and according to the validated equations [21].

\section{Statistical methods}

The Shapiro-Wilk test was used for the normality testing of numerical data, which were presented as the mean \pm standard deviation or as the median (range). Numerical variables were compared using the ANOVA or Kruskal-Wallis test. Categorical variables were presented as frequencies; the frequency distribution among different groups of patients was tested using the Fisher exact test or Chi square test for a trend. For a pair comparison of numerical variables, a paired $t$ test or Wilcoxon signed-rank test was employed. The relationship between the numerical variables was tested using a Pearson correlation or Spearman's rank correlation. All the analyses were performed using the SPSS version 22.0 (Chicago, IL, USA) and two-sided statistical tests, with a $p$ value of $\leq 0.05$ considered as being statistically significant.

\section{Results}

Between February 2017 and January 2018, 49 patients with locally advanced SCCHN entered the study. Four patients withdrew their consent before completing the study; two patients died during treatment and in three patients, a noncompliance with the inclusion criteria was discovered before starting their therapies. Thus, 40 male patients completed the whole set of study-related investigations at all three time points and their clinical characteristics are presented in Table 1. All patients completed their treatment as planned. The median time interval between assessment 1 and the commencement of RT was $15.15 \pm 3.61$ days, and between RT completion and assessments 2 and 3, it was $0.75 \pm 6.26 .74$ days and $90.53 \pm 8.94$ days, respectively.

The mean HADS-A and HADS-D scores collected in all three measurements were $4.23 \pm 3.06$ (range $0-15$ ) and $4.06 \pm 3.17$ (range $0-16$ ), respectively. The distribution of patients according to the results of the HADS sub-questionnaires is shown in Table 2. High rates of anxiety were found before treatment, whereas the depression prevalence was higher at the end and after therapy. The statistically significant differences were only recorded in the case of HADS-A: before treatment, statistically significant more patients were screened positive for psychological distress than at treatment completion $(p=0.037)$ and the same trend was seen at assessment $3(p=0.083)$.
Table 1 Characteristics of patients, tumors and treatment

\begin{tabular}{ll}
\hline Characteristic & No. of patients \\
\hline Age & $62.5(7.61)^{\mathrm{a}}$ \\
Smoking status & \\
Active smokers $^{\mathrm{b}}$ & $22(55 \%)$ \\
Former smokers $^{\mathrm{c}}$ & $13(32.5 \%)$ \\
Non-smokers & $5(12.5 \%)$ \\
Primary tumor site & \\
Oral cavity & $7(17.5 \%)$ \\
Oropharynx & $21(52.5 \%)$ \\
Hypopharynx & $7(17.5 \%)$ \\
Larynx & $5(12.5 \%)$ \\
TNM stage & \\
III & $7(17.5 \%)$ \\
IVA & $27(67.5 \%)$ \\
IVB & $6(15 \%)$ \\
HPV related primary tumors ${ }^{\mathrm{d}}$ & $7(33.3 \%)$ \\
Tracheostomy before RT & $6(15 \%)$ \\
Surgery before RT & $17(42.5 \%)$ \\
RT dose & $66.6 \mathrm{~Gy}(60-70)^{\mathrm{e}}$ \\
Duration of RT & 46.9 days $(40-55)^{\mathrm{e}}$ \\
Concurrent chemotherapy & \\
Yes & $21(52.5 \%)$ \\
No. of cycles & $6(3-7)^{\mathrm{d}}$ \\
\hline${ }^{\mathrm{a}}$ In years, mean (standard deviation) & \\
${ }^{\mathrm{b}} 20$ cigarettes/day for $\geq 10$ years & \\
${ }^{\mathrm{c}}$ Quite smoking $\geq 12$ months ago & \\
${ }^{\mathrm{e}}$ Mropharyngeal primary tumors & \\
& \\
\hline & \\
Median (range) & \\
\hline
\end{tabular}

Due to the loss of more than $5 \%$ of body weight, 5 $(12.5 \%)$ patients had a feeding-tube placement before the commencement of therapy and in an additional two patients it was inserted during treatment; at the last assessment, 4 (10\%) patients were still feeding-tube dependent. Before, at the end and 3 months after therapy, the nutritional support in the form of commercially available high caloric oral or enteral (via feeding tube) liquid nutritional supplements was used in $6(15 \%), 26(62.5 \%)$, and $22(55 \%)$ of the patients, respectively.

The results of NRS-2002, anthropometric and laboratory tests, and PA measurements are shown in Table 3. Before treatment, there were more well-nourished and less cachectic patients than at assessment $2(p=0.014)$ or assessment 3 $(p=0.140)$. The PA values were significantly higher at the initial measurement compared to both subsequent measurements $(p=0.019$ and $p=0.005)$. The pre-treatment mean value of PA $\left(5.18^{\circ}\right)$ was employed as a cut-off to sort the patients into two groups $\left(<5.18^{\circ}\right.$ vs. $\left.\geq 5.18^{\circ}\right)$ but it was found to be unrelated to the nutritional status determined by the standard tests and measurements $(p>0.05)$ (Table 3$)$. 
Table 2 Results of the HADS questionnaire

\begin{tabular}{lcccc}
\hline HADS & Assessment 1 & Assessment 2 & Assessment 3 & $p$ value $^{\mathrm{c}}$ \\
\hline HADS-A $^{\mathrm{a}}$ & $5.07(3.14)$ & $3.67(2.30)$ & $3.95(3.49)$ & $0.009 / 0.501 / 0.004$ \\
No distress $^{\mathrm{b}}$ & $29(72.5 \%)$ & $37(92.5 \%)$ & $36(90 \%)$ & $0.037 / 1.000 / 0.083$ \\
Distress $^{\mathrm{b}}$ & $11(27.5 \%)$ & $3(7.5 \%)$ & $4(10 \%)$ & \\
HADS-D $^{\mathrm{a}}$ & $3.65(2.81)$ & $4.56(2.94)$ & $3.97(3.69)$ & $0.136 / 0.286 / 0.578$ \\
No disress $^{\mathrm{b}}$ & $37(92.5 \%)$ & $34(85 \%)$ & $34(85 \%)$ & $0.381 / 1.000 / 0.481$ \\
Distress $^{\mathrm{b}}$ & $3(7.5 \%)$ & $6(15 \%)$ & $6(15 \%)$ & \\
\hline
\end{tabular}

${ }^{\text {a }}$ Scores; mean (standard deviation)

${ }^{\mathrm{b}}$ Number of patients

${ }^{c}$ Assessment 1 vs. 2/assessment 2 vs. 3/assessment 1 vs. 3

\begin{tabular}{|c|c|c|c|c|}
\hline Test/status & Assessment 1 & Assessment 2 & Assessment 3 & $p$ value $^{\mathrm{d}}$ \\
\hline \multicolumn{5}{|l|}{ Test } \\
\hline NRS 2002 (points) ${ }^{\mathrm{a}}$ & $2(0-4)$ & $2(0-4)$ & $2(0-4)$ & $0.107 / 0.316 / 0.779$ \\
\hline BMI $\left(\mathrm{kg} / \mathrm{m}^{2}\right)^{\mathrm{b}}$ & $25.82(4.96)$ & $24.61(4.35)$ & 23.84 (4.03) & $<0.001 / 0.016 /<0.001$ \\
\hline FFMI $\left(\mathrm{kg} / \mathrm{m}^{2}\right)^{\mathrm{b}}$ & $19.17(3.32)$ & $18.28(2.92)$ & $18.10(2.47)$ & $<0.000 / 0.464 / 0.004$ \\
\hline Muscle strength $(\mathrm{kg})^{\mathrm{b}}$ & 34.75 (11.17) & $33.86(11.73)$ & $32.76(10.22)$ & $0.345 / 0.269 / 0.018$ \\
\hline Hemoglobin $\left(\mathrm{g} / \mathrm{l}^{\mathrm{b}}\right.$ & $135.25(14.46)$ & $127.42(16.38)$ & $130.47(15.73)$ & $0.003 / 0.160 / 0.064$ \\
\hline $\mathrm{CRP}\left(\mathrm{mg} / \mathrm{l}^{\mathrm{a}}\right.$ & $5(1-75)$ & $16.50(1-170)$ & $4.50(0-126)$ & $<0.001 /<0.001 / 0.786$ \\
\hline Albumin $\left(\mathrm{g} / \mathrm{l}^{\mathrm{b}}\right.$ & 44.15 (4.34) & $41.73(4.53)$ & $44.42(4.08)$ & $<0.001 /<0.001 / 0.961$ \\
\hline $\mathrm{PA}\left({ }^{\circ}\right)^{\mathrm{b}}$ & $5.18(0.88)$ & $4.95(0.75)$ & $4.86(0.90)$ & $0.019 / 0.368 / 0.005$ \\
\hline \multicolumn{5}{|l|}{ Nutritional status ${ }^{\mathrm{c}}$} \\
\hline Well-nourished & $29(72.5 \%)$ & $22(55 \%)$ & $26(65 \%)$ & $0.014 / 0.320 / 0.140$ \\
\hline Malnourished & $8(20 \%)$ & $4(10 \%)$ & $4(10 \%)$ & \\
\hline Cachectic & $3(7.5 \%)$ & $14(35 \%)$ & $10(25 \%)$ & \\
\hline $\mathrm{PA}<5.2^{\circ}$ & $19(47.5 \%)$ & $24(60 \%)$ & $25(62.5 \%)$ & $0.370 / 1.000 / 0.261$ \\
\hline $\mathrm{PA} \geq 5.2^{\circ}$ & $21(52.5 \%)$ & $16(40 \%)$ & $15(37.5 \%)$ & \\
\hline
\end{tabular}

$B M I$ Body mass index, FFMI fat-free mass index, $C R P$ C-reactive protein, $P A$ phase angle

${ }^{a}$ Median (range)

${ }^{\mathrm{b}}$ Mean (standard deviation)

${ }^{\mathrm{c}}$ Number of patients

${ }^{\mathrm{d}}$ Assessment 1 vs. 2 /assessment 2 vs. 3/assessment 1 vs. 3
Different clinical factors (age, smoking status, primary tumor site, disease stage, surgery before RT, concurrent chemotherapy, HPV status, and a tracheostomy before RT) were tested to determine their influence on either the nutritional or psychological status of the patients. At treatment completion, all six patients with depressive symptoms had up-front RT (RT vs. surgery: 26.1 vs. $0 \%, p=0.030$ ) and received concurrent chemotherapy (yes vs. no: 28.6 vs. $0 \%$, $0.021)$. In respect to the nutritional status, significantly more patients with baseline $\mathrm{PA} \geq 5.2^{\circ}$ (i.e. at assessment 1) were treated with up-front RT (RT vs. surgery: 69.6 vs. $29.4 \%$, $p=0.24$ ) and concurrent chemotherapy (yes vs. no: 71.4 vs. $31.6 \%, p=0.025)$.

The correlation between psychological and conventionally determined nutritional status is presented in Table 4 .
At assessments 1 and 2, the majority of patients without psychological distress revealed by HADS-A were wellnourished, whereas distress was more often recorded among malnourished/cachectic patients $(p=0.017$ and $p=0.020$ ). According to the HADS-D, significantly more malnourished/cachectic patients than well-nourished ones were found distressed at assessments 2 and 3 ( $p=0.045$ and $p=0.023$ ). When the results of the HADS-A and HADS-D were compared with the PA values, only a weak negative correlation was recorded at all three assessment points $(p>0.05)$. However, patients with no psychological distress determined at assessment 3 using the HADS-A had statistically significant higher median PA value (4.9, range 2.3-6.5) compared to those with distress (4.1, range $3.6-4.5 ; p=0.027)$. 
Table 4 Relationship between the psychological and nutritional status

\begin{tabular}{|c|c|c|c|}
\hline Nutritional status & No distress ${ }^{\mathrm{a}}$ & Distress $^{a}$ & $p$ value \\
\hline \multicolumn{4}{|l|}{ HADS-A } \\
\hline \multicolumn{4}{|l|}{ Assessment 1} \\
\hline Well nourished & $24(82.8 \%)$ & $5(45.4 \%)$ & 0.017 \\
\hline Malnourished & $4(13.8 \%)$ & $4(36.4 \%)$ & \\
\hline Cachectic & $1(3.4 \%)$ & $2(18.2 \%)$ & \\
\hline \multicolumn{4}{|l|}{ Assessment 2} \\
\hline Well nourished & $22(59.5 \%)$ & 0 & 0.020 \\
\hline Malnourished & $4(10.8 \%)$ & 0 & \\
\hline Cachectic & $11(29.7 \%)$ & $3(100 \%)$ & \\
\hline \multicolumn{4}{|l|}{ Assessment 3} \\
\hline Well nourished & $24(66.7 \%)$ & $2(50 \%)$ & 0.327 \\
\hline Malnourished & $4(11.1 \%)$ & 0 & \\
\hline Cachectic & $8(22.2 \%)$ & $2(50 \%)$ & \\
\hline \multicolumn{4}{|l|}{ HADS-D } \\
\hline \multicolumn{4}{|l|}{ Assessment 1} \\
\hline Well nourished & $27(73 \%)$ & $2(66.7 \%)$ & 0.353 \\
\hline Malnourished & $8(21.6 \%)$ & 0 & \\
\hline Cachectic & $2(5.4 \%)$ & $1(33.3 \%)$ & \\
\hline \multicolumn{4}{|l|}{ Assessment 2} \\
\hline Well nourished & $21(61.8 \%)$ & $1(16.7 \%)$ & 0.045 \\
\hline Malnourished & $3(8.8 \%)$ & $1(16.7 \%)$ & \\
\hline Cachectic & $10(29.4 \%)$ & $4(66.6 \%)$ & \\
\hline \multicolumn{4}{|l|}{ Assessment 3} \\
\hline Well nourished & $24(70.6 \%)$ & $2(33.3 \%)$ & 0.023 \\
\hline Malnourished & $4(11.8 \%)$ & 0 & \\
\hline Cachectic & $6(17.6 \%)$ & $4(66.7 \%)$ & \\
\hline
\end{tabular}

${ }^{a}$ Number of patients

\section{Discussion}

In the present study, in the cohort of Slovenian HNC patients treated with (chemo)RT we found that their psychological and nutritional status were interconnected. Because of possible differences in the perception of a diagnosis of malignancy in different cultural and socioeconomic environments and, consequently, a potential variability in the resulting level of psychological distress, this information is of importance. In addition, the existence of a link between the two conditions has been recognized in other chronic illnesses; however, information from the HNC patients is scanty, though they have higher levels of psychological disorder and malnutrition than many other patients' groups [22]. Singer et al. found that at admission and 6 months after admission these patients suffered from symptoms of depression and anxiety 1.5 -fold and 2.7-fold, respectively, more frequently than the other patients with cancer [8]. Moreover, in a comparable cohort of patients from our previous research, one third of the patients were found malnourished or even cachectic at diagnosis and this proportion raised to $83.6 \%$ at the completion of treatment [19].

To assess the psychological state of our patients, we used the HADS questionnaire with the cut-off sum of 7 points on each of the subscales (HADS-A, HADS-D) to distinguished distressed patients from others [15]. In our group, the prevalence of anxiety was highest before treatment, whereas the HADS-A scores dropped significantly at the time of treatment completion and the same trend was observed 3 months' post-therapy. The same pattern in score changes was reported by other authors and presumably reflects the anticipatory fear presented before the start of treatment, when a "naive" patient is awaiting treatment that she/he does not know and from which she/he has no idea what to expect. It is, therefore, a fear of the unknown which disappears during the course of treatment $[6,9,23,24]$. To the contrary and in line with other studies, time variations in the HADS-D scores, although non-significant, showed that depressive symptoms peaked at the end of treatment. The delayed accumulation of symptoms of depression can be attributed to the cumulative effect of fatigue growing during treatment and to other treatment-related side effects to which the patient is exposed and usually increase during the course of treatment, reaching the peak towards its end [6, 9, 23-25].

The nutritional status in our patients was evaluated by a standard set of tests (NRS-2002, anthropometry, laboratory) and using the BIA's PA measurement, whereas for diagnosing cachectic patients, the international consensus criteria were used $[17,18]$. The resulting distribution of the patients in three nutritional categories at each of the assessment points was as expected [11-13,19], as were the temporal changes in the PA values, pointing to the negative impact of aggressive oncological treatment and related toxicities to nutritional status [26]. In our group, nutritive deterioration occurred despite systematic nutritional counselling and support that was offered to the patients, indicating the limited range of efficiency of these activities. As shown in patients with chronic obstructive pulmonary disease, lower PA values (i.e. below 5.0) indicate not only the presence of muscle weakness and deficit but also the deficits in psychomotor speed and cognitive flexibility, which may also contribute to the lesser efficacy of nutritional counselling [27]. This suggests that a greater efficacy of nutritional therapy could be achieved with appropriate psychological support.

The pioneer research on the interaction of the psychological state and nutritional status in patients with $\mathrm{HNC}$ was performed 30 years ago by Westin et al. who demonstrated that depressive patients have a much greater likelihood of developing malnutrition 1 year after treatment completion than those without distress [28]. Until recently there has been little news in this field. In 2012, Britton et al. showed that depression in the first week of treatment with RT was an independent predictor for the development of malnutrition 
4 weeks after irradiation, with a higher predictive value compared to some other already established predictive factors, e.g. TNM stage, the use of the feeding tube and the total RT dose [22]. Moreover, the deepening of depression in HNC patients may lead to social isolation to the extent that patients refuse feeding in public [29]. In our cohort, a significant correlation was recorded between nutritional status and HADS-A scores (assessments 1 and 2) as well as HADS-D scores (assessments 2 and 3), with more distressed patients found in the malnourished/cachectic subgroups. The results of PA measurements were less indicative, though at assessment 3 , non-anxious patients had significantly higher values of PA than distressed patients. A strong and negative association between anxiety and nutritional status was observed before therapy in lung cancer patients, whereas in HNC patients Van Liew et al. demonstrated that there is a dynamic reciprocal association between depressive symptoms and weight loss over the first year after diagnosis: changes in either variable were associated with concurrent, same-month changes in the other variable [30, 31]. These observations underline the importance of the assessment and treatment of both psychological symptoms and weight loss. However, given that most risk factors for nutritional decline in $\mathrm{HNC}$ are non-modifiable (e.g., stage, site, treatment), it is noteworthy that psychological symptoms are treatable, which may lead to an improvement in nutritional status [32].

Our study has several limitations. First of all, the number of included patients was arbitrary determined and small. However, due to the complexity of the study design we correctly predicted that many patients would initially decline their participation or would discontinue co-operation after the initial agreement. Thus, during the 12-month recruitment period, only 49 patients agreed to enter the study, but barely 40 of them completed all three assessments as planned. It is possible that these nine patients had more pronounced symptoms of anxiety/depression and were consequently less motivated to continue their participation in the study. We are aware that small-numbered samples exclude the possibility of analyzing the impact of some important aspects of treatment (e.g. location and extent of surgery) and of using a multivariate analysis to study the independent role of different factors (i.e. age, primary tumor site and stage, treatment characteristics) that may influence the degree of anxiety and depression. In heterogeneous cohorts like ours, such an analysis would be desirable. However, on univariate analysis, the majority of these factors failed to show any impact on either the nutritional or psychological status of the patients; similar observation was reported by Britton et al. [22]. The observed increase of distress recorded by the HADS-D at the end of therapy and a better baseline nutritional status (according to the PA values) in those of our patients treated with primary RT and concurrent chemotherapy were according to expectations as definitive chemoradiation is certainly more burdensome for patients than RT given alone or in an adjuvant setting and should be limited only to well-nourished patients. Thus, the presented results must be interpreted with caution and the study should be considered as a pilot research: a larger study, preferably with the collection of other relevant information (e.g. alcohol consumption, family life and social status, employment, etc.) is warranted.

To conclude, the relationship between the psychological and nutritional status found in this pilot study conducted in a cohort of HNC patients suggests that a larger trial is warranted to clarify the details of the observed associations and identify options for intervention.

Acknowledgements This work was financially supported by the Slovenian Research Agency (program no.P3-0307).

\section{Compliance with ethical standards}

Conflict of interest The authors declare that they have no conflict of interest.

Open Access This article is licensed under a Creative Commons Attribution 4.0 International License, which permits use, sharing, adaptation, distribution and reproduction in any medium or format, as long as you give appropriate credit to the original author(s) and the source, provide a link to the Creative Commons licence, and indicate if changes were made. The images or other third party material in this article are included in the article's Creative Commons licence, unless indicated otherwise in a credit line to the material. If material is not included in the article's Creative Commons licence and your intended use is not permitted by statutory regulation or exceeds the permitted use, you will need to obtain permission directly from the copyright holder. To view a copy of this licence, visit http://creativecommons.org/licenses/by/4.0/.

\section{References}

1. Bray F, Ferlay J, Soerjomataram I, Siegel RL, Torre LA, Jemal A (2018) Global cancer statistics 2018: GLOBOCAN estimates of incidence and mortality worldwide for 36 cancers in 185 countries. CA Cancer J Clin 68:394-424. https://doi.org/10.3322/caac.21492

2. Rogers SN, Staunton A, Girach R, Langton S, Lowe D (2019) Audit of the two-week pathway for patients with suspected cancer of the head and neck and the influence of socioeconomic status. Br J Oral Maxillofac Surg 57:419-424. https://doi.org/10.1016/j. bjoms.2018.09.016

3. Lyhne NM, Christensen A, Alanin MC, Bruun MT, Jung TH, Bruhn MA, Jespersen JB, Kristensen CA, Andersen E, Godballe C, Buchwald C, Bundgaard T, Johansen J, Lambertsen K, Primdahl H, Toustrup K, Sørensen JA, Overgaard J, Grau C (2013) Waiting times for diagnosis and treatment of head and neck cancer in Denmark in 2010 compared to 1992 and 2002. Eur J Cancer 49:1627-1633. https://doi.org/10.1016/j.ejca.2012.11.034

4. Dunne S, Mooney O, Coffey L, Sharp L, Desmond D, Timon C, O'Sullivan E, Gallagher P (2017) Psychological variables associated with quality of life following primary treatment for head and neck cancer: a systematic review of the literature from 2004 to 2015. Psychooncology 26:149-160. https://doi.org/10.1002/ pon.4109 
5. Fan CY, Chao HL, Lin CS, Huang WY, Chen CM, Lin KT, Lin CL, Kao CH (2018) Risk of depressive disorder among patients with head and neck cancer: a nationwide population-based study. Head Neck 40:312-323. https://doi.org/10.1002/hed.24961

6. Joseph LA, Routledge JA, Burns MP, Swindell R, Sykes AJ, Slevin NJ, Davidson SE (2013) Value of the hospital anxiety and depression scale in the follow up of head and neck cancer patients. J Laryngol Otol 127:285-294. https://doi.org/10.1017/ S0022215113000078

7. Nilsen ML, Mady LJ, Hodges J, Wasserman-Wincko T, Johnson JT (2019) Burden of treatment: reported outcomes in a head and neck cancer survivorship clinic. Laryngoscope 129:E437-E444. https://doi.org/10.1002/lary.27801

8. Singer S, Krauss O, Keszte J, Siegl G, Papsdorf K, Severi E, Hauss J, Briest S, Dietz A, Brähler E, Kortmann RD (2012) Predictors of emotional distress in patients with head and neck cancer. Head Neck 34:180-187. https://doi.org/10.1002/hed.21702

9. Hammerlid E, Ahlner-Elmqvist M, Bjordal K, Biörklund A, Evensen J, Boysen M, Jannert M, Kaasa S, Sullivan M, Westin T (1999) A prospective multicentre study in Sweden and Norway of mental distress and psychiatric morbidity in head and neck cancer patients. Br J Cancer 80:766-774

10. Kam D, Salib A, Gorgy G, Patel TD, Carniol ET, Eloy JA, Baredes S, Park RC (2015) Incidence of suicide in patients with head and neck cancer. JAMA Otolaryngol Head Neck Surg 141:10751081. https://doi.org/10.1001/jamaoto.2015.2480

11. Van Cutsem E, Arends J (2005) The causes and consequences of cancer-associated malnutrition. Eur J Oncol Nurs 9(Suppl 2):S51-S63

12. Gyan E, Raynard B, Durand JP, Lacau Saint Guily J, Gouy S, Movschin ML, Khemissa F, Flori N, Oziel-Taieb S, Bannier Braticevic C, Zeanandin G, Hebert C, Savinelli F, Goldwasser F, Hébuterne X, NutriCancer2012 Investigator Group (2018) Malnutrition in patients with cancer: comparison of perceptions by patients, relatives, and physicians-results of the NutriCancer2012 study. J Parenter Enteral Nutr 42:255-260. https://doi. org/10.1177/0148607116688881

13. de Pinho NB, Martucci RB, Rodrigues VD, D’Almeida CA, Thuler LCS, Saunders C, Jager-Wittenaar H, Peres WAF (2019) Malnutrition associated with nutrition impact symptoms and localization of the disease: results of a multicentric research on oncological nutrition. Clin Nutr 38:1274-1279. https://doi. org/10.1016/j.clnu.2018.05.010

14. Gorenc M, Kozjek NR, Strojan P (2015) Malnutrition and cachexia in patients with head and neck cancer treated with (chemo)radiotherapy. Rep Pract Oncol Radiother 20:249-258. https://doi.org/10.1016/j.rpor.2015.03.001

15. Zigmond AS, Snaith RP (1983) The hospital anxiety and depression scale. Acta Psychiatr Scand 67:361-370

16. Kondrup J, Allison SP, Elia M, Vellas B, Plauth M, Educational and Clinical Practice Committee, European Society of Parenteral and Enteral Nutrition (ESPEN) (2003) ESPEN guidelines for nutrition screening 2002. Clin Nutr 22:415-421

17. Fearon K, Strasser F, Anker SD, Bosaeus I, Bruera E, Fainsinger RL, Jatoi A, Loprinzi C, MacDonald N, Mantovani G, Davis M, Muscaritoli M, Ottery F, Radbruch L, Ravasco P, Walsh D, Wilcock A, Kaasa S, Baracos VE (2011) Definition and classification of cancer cachexia: an international consensus. Lancet Oncol 12:489-495. https://doi.org/10.1016/S1470-2045(10)70218-7

18. Evans WJ, Morley JE, Argilés J, Bales C, Baracos V, Guttridge D, Jatoi A, Kalantar-Zadeh K, Lochs H, Mantovani G, Marks D, Mitch WE, Muscaritoli M, Najand A, Ponikowski P, Rossi Fanelli F, Schambelan M, Schols A, Schuster M, Thomas D, Wolfe R, Anker SD (2008) Cachexia: a new definition. Clin Nutr 27:793799. https://doi.org/10.1016/j.clnu.2008.06.013
19. Stegel P, Kozjek NR, Brumen BA, Strojan P (2016) Bioelectrical impedance phase angle as indicator and predictor of cachexia in head and neck cancer patients treated with (chemo)radiotherapy. Eur J Clin Nutr 70:602-606. https://doi.org/10.1038/ejcn.2016.13

20. Peters MJ, van Nes SI, Vanhoutte EK, Bakkers M, van Doorn PA, Merkies IS, Faber CG, PeriNomS Study group (2011) Revised normative values for grip strength with the Jamar dynamometer. J Peripher Nerv Syst 16:47-50. https://doi.org/10.111 1/j.1529-8027.2011.00318.x

21. Barbosa-Silva MC, Barros AJ (2005) Bioelectrical impedance analysis in clinical practice: a new perspective on its use beyond body composition equations. Curr Opin Clin Nutr Metab Care 8:311-317

22. Britton B, Clover K, Bateman L, Odelli C, Wenham K, Zeman A, Carter GL (2012) Baseline depression predicts malnutrition in head and neck cancer patients undergoing radiotherapy. Support Care Cancer 20:335-342. https://doi.org/10.1007/s0052 0-011-1087-y

23. Wu YS, Lin PY, Chien CY, Fang FM, Chiu NM, Hung CF, Lee Y, Chong MY (2016) Anxiety and depression in patients with head and neck cancer: 6-month follow-up study. Neuropsychiatr Dis Treat 12:1029-1036. https://doi.org/10.2147/NDT.S103203

24. Henry M, Fuehrmann F, Hier M, Zeitouni A, Kost K, Richardson K, Mlynarek A, Black M, MacDonald C, Chartier G, Zhang X, Rosberger Z, Frenkiel S (2019) Contextual and historical factors for increased levels of anxiety and depression in patients with head and neck cancer: a prospective longitudinal study. Head Neck 41:2538-2548. https://doi.org/10.1002/hed.25725

25. Chen AM, Jennelle RL, Grady V, Tovar A, Bowen K, Simonin P, Tracy J, McCrudden D, Stella JR, Vijayakumar S (2009) Prospective study of psychosocial distress among patients undergoing radiotherapy for head and neck cancer. Int J Radiat Oncol Biol Phys 73:187-193. https://doi.org/10.1016/j.ijrobp.2008.04.010

26. van den Berg MG, Rasmussen-Conrad EL, Gwasara GM, Krabbe PF, Naber AH, Merkx MA (2006) A prospective study on weight loss and energy intake in patients with head and neck cancer, during diagnosis, treatment and revalidation. Clin Nutr 25:765-772

27. Rotovnik Kozjek N, Lieben C, Deutz N, Engelen M (2017) Low bioimpedance phase angle indicates muscle catabolism and loss of muscle and cognitive function in chronic obstructive pulmonary disease. Clin Nutr 36(Suppl 1):S244 (MON-P178). https://doi. org/10.1016/S0261-5614(17)30909-3

28. Westin T, Jansson A, Zenckert C, Hällström T, Edström S (1988) Mental depression is associated with malnutrition in patients with head and neck cancer. Arch Otolaryngol Head Neck Surg 114:1449-1453

29. Howren MB, Christensen AJ, Karnell LH, Funk GF (2010) Health-related quality of life in head and neck cancer survivors: impact of pretreatment depressive symptoms. Health Psychol 29:65-71. https://doi.org/10.1037/a0017788

30. Chabowski M, Polański J, Jankowska-Polańska B, Janczak D, Rosińczuk J (2018) Is nutritional status associated with the level of anxiety, depression and pain in patients with lung cancer? J Thorac Dis 10:2303-2310. https://doi.org/10.21037/ jtd.2018.03.108

31. Van Liew JR, Brock RL, Christensen AJ, Karnell LH, Pagedar NA, Funk GF (2017) Weight loss after head and neck cancer: a dynamic relationship with depressive symptoms. Head Neck 39:370-379. https://doi.org/10.1002/hed.24601

32. Britton B, Baker A, Clover K, McElduff P, Wratten C, Carter G (2017) Heads up: a pilot trial of a psychological intervention to improve nutrition in head and neck cancer patients undergoing radiotherapy. Eur J Cancer Care (Engl) 26:e12502. https://doi. org/10.1111/ecc.12502

Publisher's Note Springer Nature remains neutral with regard to jurisdictional claims in published maps and institutional affiliations. 